\title{
Ultrahigh field MRI in clinical neuroimmunology: a potential contribution to improved diagnostics and personalised disease management
}

\author{
Tim Sinnecker ${ }^{1,2}$, Joseph Kuchling ${ }^{1}$, Petr Dusek ${ }^{3,4}$, Jan Dörr ${ }^{1,5}$, Thoralf Niendorf ${ }^{6,7}$, Friedemann Paul $^{1,5,7,8^{*}+}$
} and Jens Wuerfel ${ }^{1,3,6,9+}$

\begin{abstract}
Conventional magnetic resonance imaging (MRI) at 1.5 Tesla (T) is limited by modest spatial resolution and signal-to-noise ratio (SNR), impeding the identification and classification of inflammatory central nervous system changes in current clinical practice. Gaining from enhanced susceptibility effects and improved SNR, ultrahigh field MRI at 7 T depicts inflammatory brain lesions in great detail. This review summarises recent reports on $7 \mathrm{~T}$ MRI in neuroinflammatory diseases and addresses the question as to whether ultrahigh field MRI may eventually improve clinical decision-making and personalised disease management.
\end{abstract}

Keywords: 7 Tesla, Ultrahigh field MRI, Multiple sclerosis, Neuromyelitis optica, Susac syndrome, Neuroimmunology, Central vein sign, Cortical lesions, Predictive, Preventive and Personalised Medicine

\section{Review}

Introduction

Magnetic resonance imaging (MRI) revolutionised clinical neuroimmunology since brain MRI depicted multiple sclerosis (MS) lesions already in early technical developmental stages at 0.1 Tesla (T) [1]. During the past decade, MRI became a crucial tool to diagnose and monitor inflammatory central nervous system (CNS) alterations [2]. Nonetheless, today's physicians are faced with a key issue in clinical neurology: many distinct CNS diseases are characterised by nearly identically appearing white matter changes and brain lesions that are often unspecific in appearance, limiting the diagnostic value of conventional MRI.

Ultrahigh field (UHF) MRI at $7 \mathrm{~T}$ benefits from increased signal-to-noise ratio (SNR) and enhanced spatial resolution as good as $100 \mu \mathrm{m}$ [3]. Future studies will show whether these $7 \mathrm{~T}$ MRI advantages indeed improve diagnosis and our understanding of the underlying pathophysiology in

\footnotetext{
* Correspondence: friedemann.paul@charite.de

${ }^{\dagger}$ Equal contributors

${ }^{1}$ NeuroCure Clinical Research Center (NCRC), Charité - Universitaetsmedizin Berlin, Charitéplatz 1, 10117 Berlin, Germany

${ }^{5}$ Clinical and Experimental Multiple Sclerosis Research Center, Department of Neurology, Charité Universitaetsmedizin Berlin, Charitéplatz 1, 10117 Berlin, Germany

Full list of author information is available at the end of the article
}

inflammatory CNS diseases. Following the recommendations of the "EPMA White Paper" [4], this review summarises technical opportunities, challenges, and findings of recent clinical $7 \mathrm{~T}$ MRI studies on multiple sclerosis, neuromyelitis optica, and Susac syndrome.

\section{Technical improvements and limitations}

SNR is a key factor in MRI and the currency spent for diagnostic accuracy. Although the level of background noise increases proportionally with magnetic field strengths, the magnitude of the MR signal even gains by square [5], causing the SNR to increase nearly linearly with the magnetic field strength [6]. Consequently, increased SNR at $7 \mathrm{~T}$ can be used to acquire MR images of very high spatial resolution, e.g., up to $0.08 \mathrm{~mm}^{3}$ (Fig. 1). Furthermore, UHF MRI benefits (and sometimes suffers) from increased susceptibility effects that are caused by, e.g., paramagnetic or ferromagnetic substances such as iron species (mostly ferritin and haemosiderin) and deoxyhaemoglobin. These microscopic disturbances of the magnetic field on cellular and tissue levels cause a focal signal loss resulting from dephasing spins during gradient echo image acquisitions and a positive (paramagnetic) phase shift of the MR signal. Hence, not only very small brain structures containing paramagnetic 


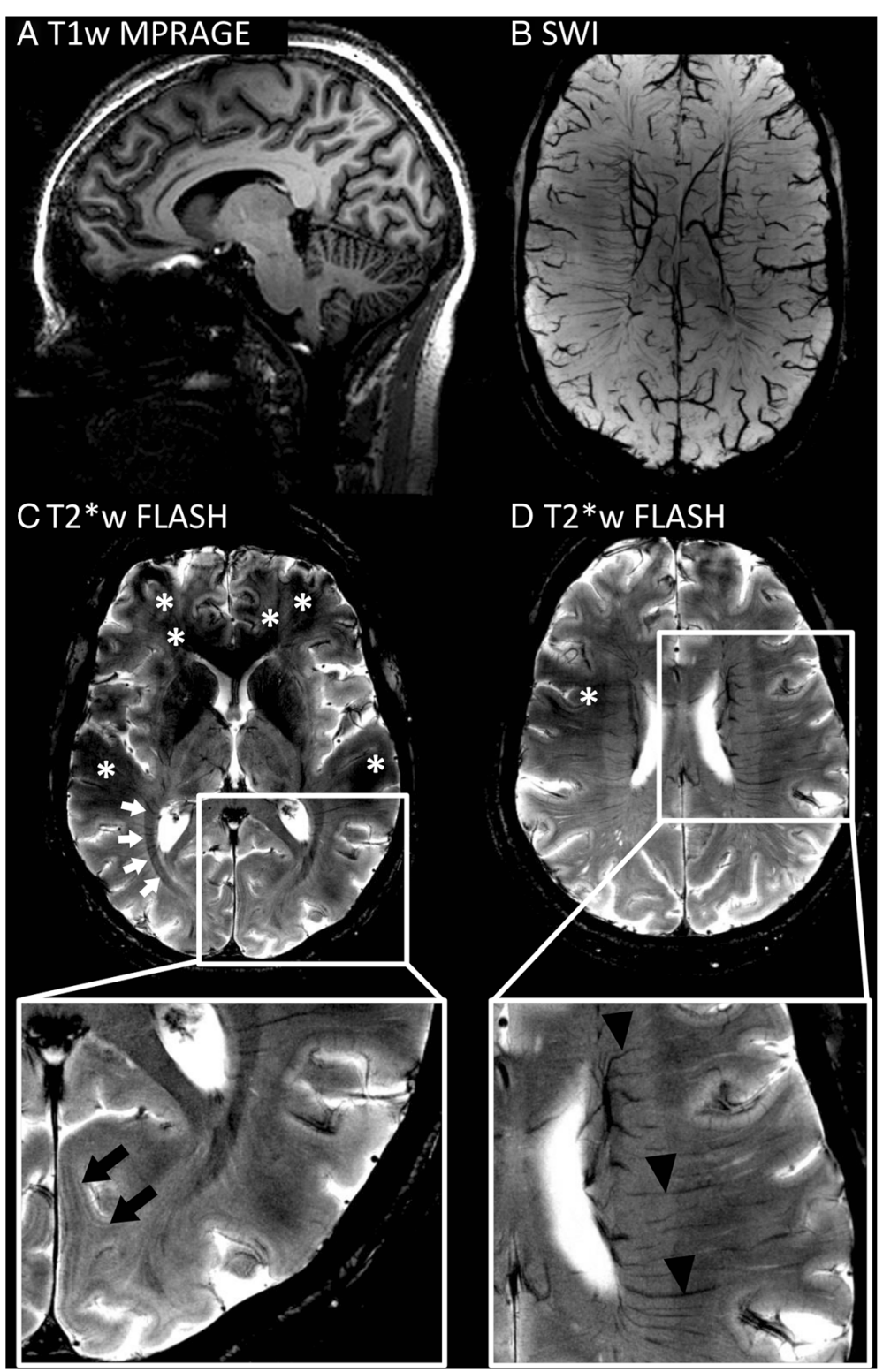

Fig. 1 Brain structures visualised on 7 Tesla MRI images. a 7 T T1w MPRAGE provides high-resolution anatomical imaging with excellent gray to white matter contrast. $\mathbf{b} 7 \mathrm{~T}$ SWI depicts very small brain veins. $\mathbf{c}$, $\mathbf{d} 7$ T T2* ${ }^{*} \mathrm{FLASH}$ with a resolution of $0.2 \mathrm{~mm} \times 0.2 \mathrm{~mm} \times 2 \mathrm{~mm}$ delineates strongly myelinated structures such as the optic radiation (white arrows) or the stripe of Gennari (black arrows, zoom). In addition, very small veins are visualised in the periventricular white matter (black arrowheads, zoom). Nevertheless, the image quality of $7 \mathrm{~T}$ gradient echo images is sometimes reduced due to inhomogeneities or artifacts (asterisks)

substances such as veins but also highly aligned or densely myelinated structures such as the optic radiation or even the small line of Gennari that is part of the primary visual cortex may be visualised in $7 \mathrm{~T} \mathrm{T2*}$ weighted $(\mathrm{T} 2 * \mathrm{w})$ images (Fig. 1). Furthermore, deep brain stem structures such as nerve roots, or pons fibers [7], and the habenula [8] can now be visualised in great detail.

However, there are still few practical and technical considerations to be made when applying UHF MRI: Some patients may be excluded from an examination at $7 \mathrm{~T}$ due to an increased number of contraindications at UHF as compared to lower field strengths, such as tattoos, dental implants, metallic intrauterine devices, stents, surgical clips, and piercings. These may also include otherwise "MRI-safe" implants such as pacemakers or orthopaedic replacements.

Furthermore, there are technical challenges that deserve attention: Increased magnetic field inhomogeneity may impact post-processing procedures despite excellent 
gray to white matter contrast. Radiofrequency (RF) power deposition constitutes another practical challenge since it scales superlinearily with the magnetic field strength. Local RF coils that offer improved transmission efficiency versus large volume coils can be instrumental to offset this challenge [9-11].

When considering these constraints, UHF MRI is believed to be safe and it is well tolerated by the vast majority of patients $[12,13]$. Nonetheless, temporary adverse events were reported during $7 \mathrm{~T}$ at higher frequency compared to $1.5 \mathrm{~T}$ MRI [14]. In addition, $5 \%$ of all subjects or patients reported vertigo during UHF MR exams [14]. During scan with magnetic field gradients being rapidly switched, visual disturbances or temporary muscle contractions may occur [15-17]. Deteriorating vital signs or long-term effects have-to the best of our knowledge-not been described during or after $7 \mathrm{~T}$ MRI investigations $[13,18,19]$, but the relevance of preliminary in vitro studies on potential deoxyribonucleic acid (DNA) damage caused by a static magnetic field of $1.5 \mathrm{~T}$ or by rapidly changing magnetic fields is still subject to discussion [20, 21]. A recent analysis of DNA double-strand breaks (DSB) in human peripheral blood mononuclear cells after exposure to $7 \mathrm{~T}$ did not show a significant increase in DSB levels compared to the unexposed control group [16].

\section{Multiple sclerosis}

Multiple sclerosis is an inflammatory and neurodegenerative autoimmune CNS disorder affecting white as well as gray matter of the brain and spinal cord [22-24]. The disease is characterised by a wide range of symptoms and a large heterogeneity in clinical presentation. Besides neurological impairment in visual, pyramidal, cerebellar, sensory, and vegetative functional systems, more global symptoms of CNS dysfunction such as fatigue and cognitive dysfunction may occur that negatively impact patients' quality of life [23, 25-30]. MRI and more recently optical coherence tomography (OCT) have emerged as valuable imaging tools for contributing to diagnosis, differential diagnosis, and disease monitoring [31-39]. These imaging techniques have shown that beyond focal lesions, diffuse and widespread tissue damage occurs in both the gray and the white matter already in early disease stages [40-43] and more pronounced in progressive disease [44]. However, diagnosis and treatment decisions in clinical routine are still widely based on the detection of focal cerebral white matter lesions hyperintense on $\mathrm{T} 2$ weighted $(\mathrm{T} 2 \mathrm{w})$ or fluid attenuated inversion recovery (FLAIR) images. An accurate diagnosis of MS remains challenging given the insufficient specificity of focal white matter lesions $[45,46]$. In this regard, UHF MRI improves both the detection and morphological description of MS lesions and may thus be used in the future to distinguish MS from lesions of other origins and to improve our understanding of the disease. This is of high clinical relevance as the broadening MS treatment landscape will pave the way for an individualised and tailored MS therapy [47]. However, with the increasing number of available efficacious immunosuppressive and immunomodulatory drugs for MS, a correct and timely diagnosis is a prerequisite for personalised medicine that weighs benefits and risks of these drugs in every individual patient [24, 48-54].

\section{Cortical gray matter lesions}

The detection of cortical lesions is greatly improved by 7 T MRI [55]. Gray matter pathology accumulates during disease progression and may affect major areas of the cortex in long-standing multiple sclerosis [56-58]. Recent studies revealed that cortical lesions are associated with disease progression, disability, and cognitive dysfunction [59-61]. In conventional MRI, the vast majority of cortical lesions remain undetected even when applying double inversion recovery (DIR) techniques at $1.5 \mathrm{~T}$ $[62,63]$. UHF MRI at $7 \mathrm{~T}$ improves the detection of cortical lesions and depicts up to $48 \%$ of all cortical lesions revealed by ex vivo immunohistochemical staining for myelin [64]. These results were confirmed by several in vivo studies. Magnetisation transfer imaging at $7 \mathrm{~T}$ was reported to detect roughly $25 \%$ more cortical lesions than 3 T DIR in a recent study [65]. Furthermore, 7 T 3D FLAIR is highly sensitive in detecting cortical lesions and detects $89 \%$ more lesions than $7 \mathrm{~T}$ 3D DIR [66]. A multi-contrast $3 \mathrm{~T}$ versus $7 \mathrm{~T}$ comparative study reported $7 \mathrm{~T}$ MRI to detect up to $238 \%$ more cortical lesions than $3 \mathrm{~T}$ [67]. In addition, it was shown that $7 \mathrm{~T}$ T1 weighted magnetisation prepared rapid acquisition gradient echo (MPRAGE) imaging increases the detection rate of cortical lesions by twofold in comparison to $1.5 \mathrm{~T}$ MPRAGE $[65,68]$.

Owing to the high spatial resolution at UHF, cortical lesions are much easier to be differentiated from subcortical lesions-or artifacts-at $7 \mathrm{~T}$ compared to $3 \mathrm{~T}$ MRI [55]. Accordingly, an excellent inter-rater-reliability of $7 \mathrm{~T}(k=$ $0.97)$ was reported in contrast to $3 \mathrm{~T}$ DIR $(k=0.12)$ in detecting cortical lesions [69]. Most importantly, UHF MRI can differentiate the various cortical lesion subtypes as defined by histology [70], including leukocortical (type I) lesions, purely intracortical (type II) lesions, and subpial (type III/IV) lesions (Fig. 2) [71-74]. The latter were found to be very specific for MS in a histopathological study [75]. Interestingly, $7 \mathrm{~T} \mathrm{T2*}$ w fast low angle shot (FLASH) is superior over $3 \mathrm{~T}$ DIR in detecting subpial (type III/IV) lesions [69]. Accordingly, a recent study using the T2* mapping technique at $7 \mathrm{~T}$ revealed subpial $\mathrm{T} 2 *$ relaxation time changes in large cortical areas in long-standing MS [76]. In addition, thalamic gray matter lesions visualised on 7 T MRI images correlate with disability and are more often detectable in progressive MS [77]. 


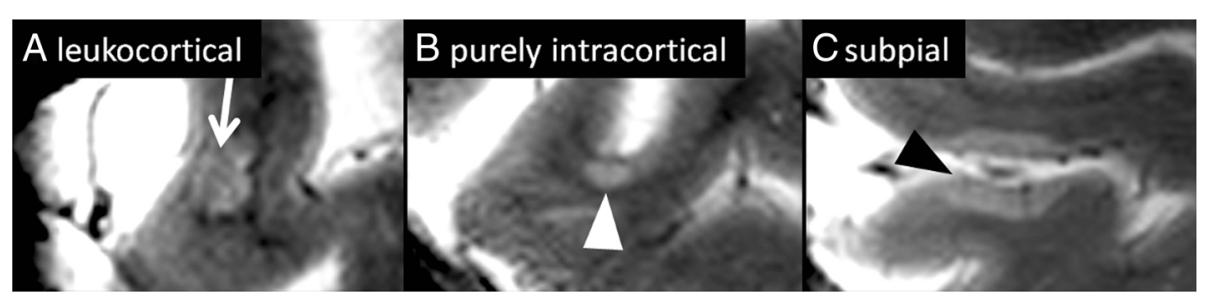

Fig. 2 Cortical gray matter lesions in multiple sclerosis. Cortical gray matter lesions can be differentiated into distinct lesion subtypes on $7 \mathrm{~T}$ T2*W images. Leukocortical (type I) lesions (a) cross the border (white arrow) between the white and the gray matter. Purely intracortical (type II) lesions (b) are commonly small and centered on a small blood vessel (white arrowhead). Finally, subpial (type III/IV) lesions (c, black arrowhead) grow from the subpial cortical area into the cortex. The purely intracortical (type II) lesion depicted in this figure has previously been published in: "Ultrahigh field MRI in context of neurological diseases." Kuchling J, Sinnecker T, Bozin I, Dörr J, Madai VI, Sobesky J, Niendorf T, Paul F, Wuerfel J. Nervenarzt. 2014;85(4):445-58. doi:10.1007/s00115-013-3967-5. [3]

In sum, there is increasing evidence that $7 \mathrm{~T}$ MRI detects significantly more (subpial) cortical lesions than $3 \mathrm{~T}$, but the detection of some type III lesions still remains challenging [69].

\section{Improved depiction of white matter lesions}

Persisting T1 weighted (T1w) hypointense lesionsnamely black holes-contribute to disability in MS in addition to cortical lesions [78, 79]. At UHF strength-and in contrast to conventional MRI at $1.5 \mathrm{~T}$-virtually, every $\mathrm{T} 2 \mathrm{w}$ hyperintense lesion is visible as a distinct hypointense plaque on $7 \mathrm{~T}$ T1w MPRAGE images as shown by our group and others $[68,80]$. Contrarily, $1.5 \mathrm{~T}$ T1w MPRAGE delineated only 68 to $78 \%$ of T2w lesions in the same study [68]. Moreover, $7 \mathrm{~T}$ T1w MPRAGE is even more sensitive in detecting MS lesions than $1.5 \mathrm{~T} \mathrm{~T} 2 \mathrm{w}$ (728 versus 545 lesions) [68] or 3 T FLAIR imaging (1043 versus 812 lesions) [80].

In contrast to these improvements, $7 \mathrm{~T} \mathrm{~T} 2 \mathrm{w}$ or FLAIR does not depict a significantly higher lesion count compared to $3 \mathrm{~T}$ T2w MRI $[67,81]$.

In conclusion, $7 \mathrm{~T}$ T1w MPRAGE is highly sensitive in detecting MS white matter lesion damage (Fig. 3a), but the T2w lesion count is not substantially increased at $7 \mathrm{~T}$ compared to $3 \mathrm{~T}$ MRI. The true advantage of $7 \mathrm{~T} \mathrm{~T} 2 \mathrm{w}$ imaging is the visualisation of very small morphological lesion details as described in the following paragraph.

\section{White matter lesion morphology}

Gaining from increased susceptibility effects and spatial resolution, $\mathrm{T} 2{ }^{*} \mathrm{w}$ imaging at $7 \mathrm{~T}$ delineates distinct morphological features of MS lesions. Most importantly, a very small vein can be displayed within the center of the MS lesion on $\mathrm{T} 2{ }^{*} \mathrm{w}$ images, and the lesion often follows the course of the vessel (Fig. 3b) [71, 73, 74, 81, 82]. This feature is not only detectable in relapsing-remitting MS but also observable in primary progressive MS [83]. In addition, a proportion of MS lesions is characterised by a $\mathrm{T} 2 * \mathrm{w}$ hypointense rim surrounding the lesion (Fig. 3b) [71, 73, 74]. A comparative $7 \mathrm{~T}$ and histopathological study found that these rims correspond to iron-rich CD68-positive cells of the macrophage lineage [73]. Hence, a positive rather thick rim-like phase shift is detectable around these lesions at $7 \mathrm{~T}$ [84]. Contrarily, rather thin rim-like phase shifts around MS lesions without major $\mathrm{T} 2 * \mathrm{w}$ hypointensity in these areas

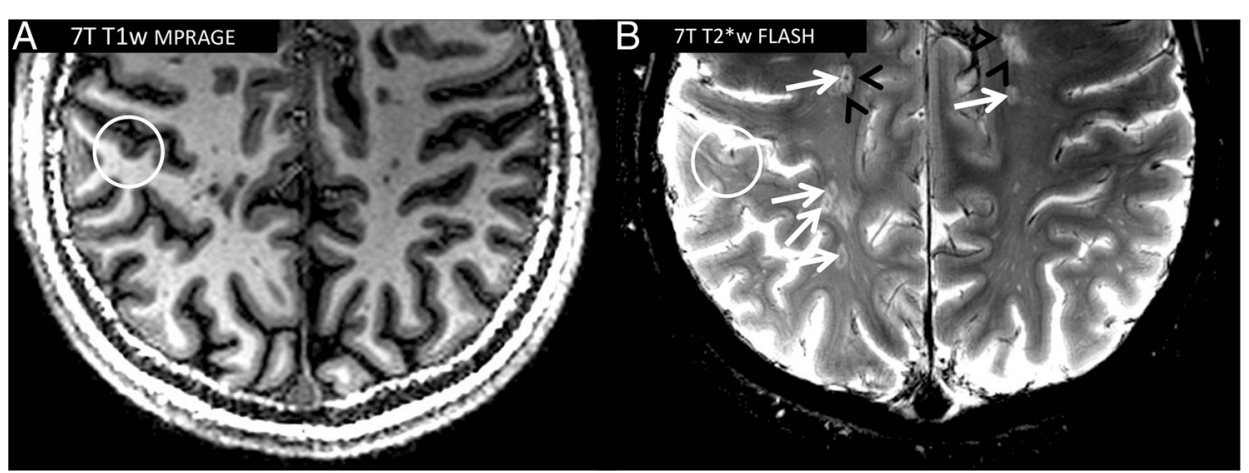

Fig. 3 Exemplary multiple sclerosis lesions. 7 T T1w MPRAGE (a, spatial resolution $1.0 \mathrm{~mm} \times 1.0 \mathrm{~mm} \times 1.0 \mathrm{~mm})$ and 7 T T2*W FLASH images (spatial resolution $0.5 \mathrm{~mm} \times 0.5 \mathrm{~mm} \times 2.0 \mathrm{~mm}$ ) are displayed. $7 \mathrm{~T} \mathrm{T2}{ }^{*} \mathrm{~W}$ FLASH delineates various multiple sclerosis white matter lesions that are centered on a small venous vessel (white arrows). In addition, a hypointense rim can be depicted at the edge of a proportion of white matter lesions (black arrowheads). A subpial (Type III/IV) lesion is visible in the right hemisphere (circle) as a T2*W hyperintensity (b) and a corresponding T1w hypointensity (a) within the cortical gray matter 
were associated with blood-brain barrier breakdown and inflammatory activity [84]. In general, MRI phase imaging can provide additional information on the tissue microstructure that is not encoded in the magnitude of the MR signal. Thus, MRI phase imaging at $7 \mathrm{~T}$ depicts white matter lesions prior to conventional $\mathrm{T} 2 \mathrm{w}$ imaging as revealed by a case series [85]. Finally, susceptibility changes indicative of iron deposition within the center of a proportion of MS lesions can be found even in the earliest MS disease stages [86]. The origin of these iron deposits, however, still remains unclear and highly speculative. Leakages of haemoglobin through a leaky blood vessel or dying iron-rich oligodendrocytes releasing iron into the extracellular matrix are only two hypotheses among many others [87-91].

\section{Differential diagnosis by 7 T MRI}

The detailed description of the lesion morphology facilitates the distinction of MS lesions versus brain lesions of other origin [92-95]. A first study on 28 MS patients and 17 subjects with non-symptomatic lesions presumably caused by small vessel disease found that the "central vein sign" differentiates MS patients from these controls by using a central vein cutoff of $40 \%$ [94]. The same cutoff was reported to be beneficial in predicting MS conversion of clinically isolated syndrome (CIS) patients [96]. In detail, each of 13 CIS patients with a positive central vein sign $(>40 \%)$ at baseline included in a prospective study developed MS, and all CIS patients $(n=9)$ with a negative central vein sign $(<40 \%)$ at baseline were ultimately diagnosed as not having MS [96]. The median follow-up time in this study was 26 months (range, 4-37 months) [96]. Although these initial results must be confirmed in a larger dataset with longer follow-up, this study illustrates the potential predictive capability of $7 \mathrm{~T}$ MRI.

\section{Venous abnormalities in MS}

The controversy on cerebrospinal venous insufficiency in MS [97-100] revitalised a discussion on vascular abnormalities within MS lesions that were first described by Dawson et al. in early 1916 [101]. Today, $7 \mathrm{~T}$ T2*w imaging can depict very small brain veins in vivo (Fig. 1) $[71,74,82,102]$. The venous density is reduced in MS compared to healthy controls presumably as a consequence of hypometabolism, gliosis, and vascular damage [103]. This reduction in (periventricular) venous density is already detectable in the earliest MS disease stages and patients with CIS [103]. Furthermore, shrinkage of intralesional compared to extra-lesional veins was reported recently [104]. Although the degree of intra-lesional venous shrinkage was smaller in another study [102], intralesional venous shrinking is a potential in vivo imaging marker of inflammation since it is hypothesised to be the consequence of thickened vein walls caused by inflammation leading to obstruction and reduced blood flow [105].

\section{Structural damage and atrophy in MS}

High-resolution $7 \mathrm{~T} \mathrm{T2*w}$ imaging visualises strongly myelinated aligned structures such as the optic radiation (OR, Fig. 1). Furthermore, very small lesions can be displayed within the OR on $7 \mathrm{~T}$ images [106]. The lesion volume affecting the optic radiation was reported to be associated with OR atrophy and retinal thinning as revealed by OCT [106]. This association between OR damage and retinal atrophy may reflect retrograde transsynaptic degeneration, but independent mechanisms may play a role, too.

Quantifying the total volume of brain tissue and volumes of gray or white matter is impeded at $7 \mathrm{~T}$ by the local field inhomogeneity. This limitation may be overcome by a T1w MPRAGE sequence with two inversion pulses, e.g., MPRAGE with multiple echoes (MP2RAGE), a technique recently recommended for generating a homogenised T1w image free of proton density or T2w contrast [107]. Indeed, the MP2RAGE approach yielded sufficient cortical surface reconstructions [108] and voxelbased morphometry (VBM) analyses estimating gray matter volume can be of good quality regarding superior cortical areas [109, 110].

\section{Neuromyelitis optica}

Neuromyelitis optica (NMO) is a potentially severe and disabling disease affecting primarily the spinal cord and the optic tracts [111]. Since the discovery of a pathogenic serum antibody against the astrocytic water channel aquaporin-4, it is no longer considered a variant of multiple sclerosis, but rather a disease entity of its own [112-122]. Distinct treatment regimens have been established in NMO, and drugs that are beneficial in MS might be harmful in NMO [123-128]. The distinction between NMO and MS, however, still remains puzzling in current clinical practice since brain white matter lesions - a hallmark of MS-are also detectable in more than $60 \%$ of NMO cases during the course of the disease and a subset of NMO patients exhibit short cord lesions [129-132]. NMO and MS lesions can be described in more detail in high-resolution $7 \mathrm{~T}$ MR images. As stated above, MS lesions are characteristically centered by a small vein that is easily depictable at $7 \mathrm{~T}$ gradient echo images [71, 74, 82, 102]. Recently, two independent studies-each of them included ten patients with NMO spectrum disorders-described NMO lesion morphology at $7 \mathrm{~T}[92,93]$. Firstly, brain lesions were common in NMO as expected (92 lesions [93], 140 lesions [92]). A distinct central vein, however, was not commonly observed within NMO lesions: Kister and colleagues observed a central vein within $9 \%$ (eight lesions) of all NMO lesions [93] and Sinnecker et al. detected an intralesional vein that was rarely centred within the lesion in $35 \%(n=49)$ of all NMO lesions (Fig. 4) [92]. In addition, $\mathrm{T} 2{ }^{*} \mathrm{w}$ hypointense rim-like alterations that can 


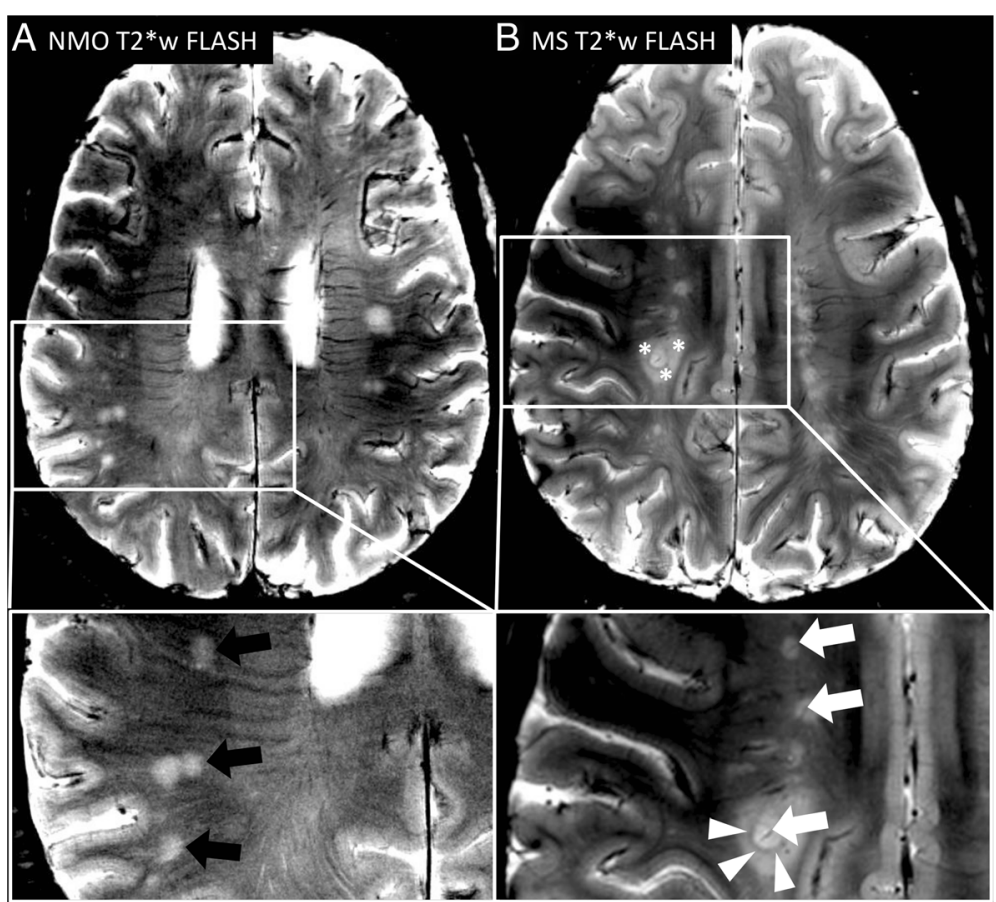

Fig. 4 Neuromyelitis optica (NMO) versus multiple sclerosis (MS) lesion morphology. 7 T T2*W FLASH images from one exemplary NMO (a) and MS (b) patient are displayed. A small central vein can be displayed within the inner third of many MS lesions (white arrows). One acute MS lesion is characterised by a hypointense rim (white arrowheads) and surrounding edema (asterisks). Contrarily, a central vessel is not visible in NMO lesions (black arrows) despite using a very high spatial resolution of $0.2 \mathrm{~mm} \times 0.2 \mathrm{~mm} \times 2 \mathrm{~mm}$

be often observed at the edge of MS plaques were only very rarely detectable around NMO lesions $(n=3)$ [92]. None of the two $7 \mathrm{~T}$ studies on NMO reported any cortical gray matter lesions in NMO patients [92, 93].

In summary, these $7 \mathrm{~T}$ MRI imaging characteristics may be used in the future to improve the differentiation between NMO and MS, which is highly relevant for the individual patient since therapeutic approaches in MS and NMO differ considerably [123-126]. The central vein sign is a potential future biomarker to distinguish MS from
NMO patients. It is noteworthy that the sensitivity in detecting venous structures on $7 \mathrm{~T}$ gradient echo images largely relates to the imaging sequence, the post-processing, and the acquisition parameters such as the spatial resolution, flip angle, or echo time [102]. Thus, a "central vein cutoff value" for the differentiation of MS versus NMO lesions may vary in relationship to these parameters. An important limitation of current studies on NMO and $7 \mathrm{~T}$ MRI is the absence of spinal cord imaging at $7 \mathrm{~T}$ and small sample sizes [92, 93].

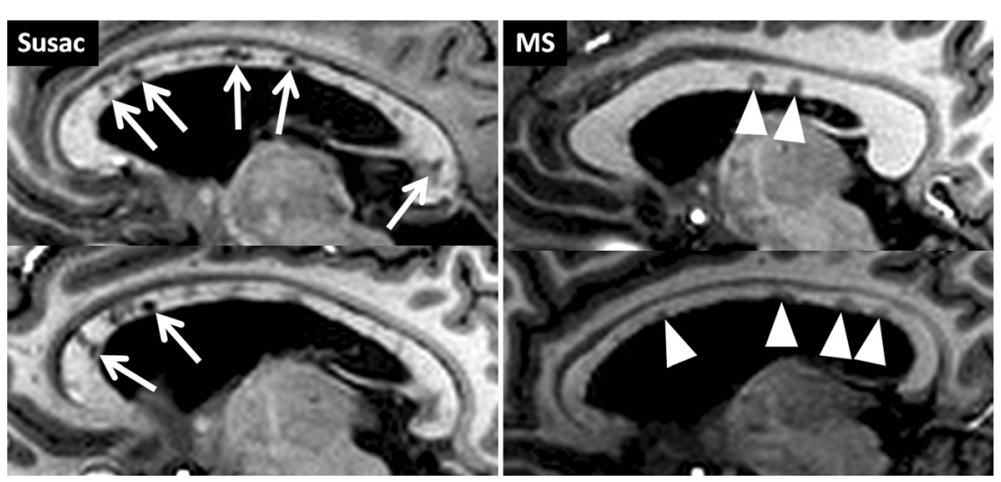

Fig. 5 Callosal damage in Susac syndrome visualised on 7 T T1w images. The figure displays 7 T T1w MPRAGE images. Susac lesions (white arrows) are typically located within the centre of the corpus callosum and are often characterised by a prominent T1 hypointensity (white arrows) indicating severe tissue destruction. Contrarily, callosal MS lesions (white arrowheads) are often located adjacent to the ventricle within peripheral areas of the corpus callosum. These typically cap-shaped MS lesions are rather characterised by a moderate T1-hypointensity 


\section{Susac syndrome}

Susac syndrome is an orphan disease that was first described by John Susac in 1979 as a clinical triad consisting of loss of vision, hearing loss, and encephalopathy that can present with headache or seizures [133]. It is considered a small vessel disease causing microinfarctions and damage to the cochlea, retina, and brain [133-140]. Susac syndrome is often a monophasic disease, but relapsingremitting disease courses were described [135, 141]. In these cases, continuous immunosuppression may be beneficial, but larger systematic studies are not available to prove this assumption $[142,143]$. Susac lesions within the corpus callosum can be imaged by MRI with a snowballlike or spike-like appearance [144]. Apart from callosal lesions, lesions are often detectable within the periventricular or deep white matter of Susac patients complicating the distinction from MS $[95,144]$. A single study of five Susac and ten MS patients investigated the morphology of Susac lesions on $7 \mathrm{~T}$ MR images [95]. At $7 \mathrm{~T}$, these lesions are rather unspecific in appearance without having a central vein or rim-like $\mathrm{T} 2{ }^{*} \mathrm{w}$ hypointense areas. In addition, callosal atrophy was detectable in many Susac patients presumably as a consequence of focal callosal damage and many cerebrospinal fluid (CSF) isointense black holes within the central part of the corpus callosum (Fig. 5). Contrarily, callosal MS lesions were often located in lateral areas of the corpus callosum showing less severe reduced T1w signal intensity values compared to Susac lesions. Future studies need to prove these initial findings in a larger sample size.

\section{Conclusions}

An increasing number of $7 \mathrm{~T}$ MRI studies described unique features of MS lesions-most importantly, the central vein sign - that may be used in the future to differentiate MS lesions from brain lesions of other origin. Today there is, however, only limited evidence on these findings since many $7 \mathrm{~T}$ MRI studies comprise small patient cohorts or are hampered by a cross-sectional design. In addition, not all differential diagnoses of MS have been investigated at $7 \mathrm{~T}$ yet. From a more technical and practical perspective, technical limitations such as magnetic field inhomogeneity and economic as well as safety concerns have to be solved before widely applying $7 \mathrm{~T}$ in clinical practice. By then, we should aim to apply knowledge from these preliminary $7 \mathrm{~T}$ MRI studies to $3 \mathrm{~T}$ MRI platforms that are available for clinical imaging. Recently, different approaches to display venous structures within MS lesions at $3 \mathrm{~T}$ were published: FLAIR* combines FLAIR and T2* $\mathrm{w}$ images $[145,146]$, whereas susceptibility weighted FLAIR (sFLAIR) combines SWI and FLAIR images [102, 147]. In addition, optimised $3 \mathrm{~T} \mathrm{T2}$ " $\mathrm{w}$ contrast may improve vessel detection at $3 \mathrm{~T}[148]$.
In the emerging field of personalised medicine, $7 \mathrm{~T}$ MRI may be used in patients with suspected neuroinflammatory disease such as MS, but conflicting clinical or paraclinical findings to support making the correct diagnosis early. Today, this should be done within the framework of clinical trials.

\section{Abbreviations}

CIS: clinically isolated syndrome; CNS: central nervous system;

CSF: cerebrospinal fluid; DIR: double inversion recovery;

DNA: deoxyribonucleic acid; DSB: deoxyribonucleic acid double-strand breaks; FLAIR: fluid attenuated inversion recovery; FLASH: fast low angle shot; MPRAGE: magnetisation prepared rapid acquisition gradient echo; MP2RAGE: MPRAGE with multiple echoes; MRI: magnetic resonance imaging; MS: multiple sclerosis; NMO: neuromyelitis optica; OCT: optical coherence tomography; OR: optic radiation; RF: radiofrequency; sFLAIR: susceptibility weighted fluid attenuated inversion recovery; SNR: signal-to-noise ratio; T: Tesla; T1w: T1 weighted; T2* $\mathrm{w}$ : T2* weighted; T2w: T2 weighted; UHF: Ultrahigh field; VBM: voxel-based morphometry.

\section{Competing interests}

TS received travel support from Bayer, Novartis, Genzyme-a Sanofi company and Teva. JK received conference registration fees from Biogen. PD is funded by the Charles University in Prague, PRVOUK P26/LF1/4 and Czech Ministry of Health, NV15-25602A grants and received honoraria for lecturing from UCB pharma. JD received research grants from Novartis and Bayer; speaker honoraria from Novartis, Bayer, Biogen, Teva, and Genzyme; compensation for advisory from Novartis, Bayer, Teva, and Genzyme; and travel support from Novartis, Bayer, and Genzyme. TN is the founder and CEO of MRI.TOOLS GmbH, Berlin, Germany. FP received funding from Deutsche Forschungsgemeinschaft (Exc 257), Bundesministerium für Bildung und Forschung (Competence Network Multiple Sclerosis KKNMS), Guthy Jackson Charitable Foundation, Arthur Arnstein Foundation, research support and personal compensation for activities with Alexion, Bayer, Biogenldec, Chugai, Medlmmmune, Novartis, Teva, Merck, and SanofiGenzyme.

\section{Authors' contributions}

TS, TN, FP, and JW conceived of the concept and design of the article. TS and JK carried out primary literature research. TS, JK, FP, JW, and JD were responsible for literature analysis and evaluation. TN and PD supervised the entire literature review process. TS drafted the manuscript. PD, JW, and FP coordinated the review process and helped to draft the manuscript. All authors provided critical revision of the manuscript for important intellectual content. JD, PD, TN, FP, and JW provided administrative, technical, and material support. All authors read and approved the final manuscript.

\section{Acknowledgements}

This work was supported by the German Research Foundation (DFG Exc 257 to FP) and by the German Ministry of Education and Research (Competence Network Multiple Sclerosis KKNMS to FP and JW) and a research grant from the Guthy Jackson Charitable Foundation/National Multiple Sclerosis Society of the USA.

\section{Author details}

${ }^{1}$ NeuroCure Clinical Research Center (NCRC), Charité - Universitaetsmedizin Berlin, Charitéplatz 1, 10117 Berlin, Germany. Department of Neurology, Asklepios Fachklinikum Teupitz, Buchholzer Str. 21, 15755 Teupitz, Germany. ${ }^{3}$ Institute of Neuroradiology, Universitaetsmedizin Goettingen, Robert-Koch-Straße 40, 37075 Goettingen, Germany. ${ }^{4}$ Department of Neurology and Center of Clinical Neuroscience, Charles University in Prague, 1st Faculty of Medicine and General University Hospital in Prague, Kateřinská 30, 12821 Praha 2, Czech Republic. ${ }^{5}$ Clinical and Experimental Multiple Sclerosis Research Center, Department of Neurology, Charité Universitaetsmedizin Berlin, Charitéplatz 1, 10117 Berlin, Germany. ${ }^{6}$ Berlin Ultrahigh Field Facility, Max Delbrueck Center for Molecular Medicine, Robert-Roessle-Strasse 10, 13125 Berlin, Germany. ${ }^{7}$ Experimental and Clinical Research Center, Charité - Universitaetsmedizin Berlin and Max Delbrueck Center for Molecular Medicine, Robert-Roessle-Strasse 10, 13125 Berlin, Germany. ${ }^{8}$ Department of Neurology, Charité - Universitaetsmedizin Berlin, Charitéplatz 1, 10117 Berlin, Germany. ${ }^{9}$ Medical Image Analysis Center, Mittlere Strasse 83, CH-4031 Basel, Switzerland. 
Received: 3 July 2015 Accepted: 20 July 2015

Published online: 27 August 2015

\section{References}

1. Holland GN, Moore WS, Hawkes RC. Nuclear magnetic resonance tomography of the brain. J Comput Assist Tomogr. 1980;4:1-3.

2. Filippi M, Rocca MA, De Stefano N, Enzinger C, Fisher E, Horsfield MA, et al. Magnetic resonance techniques in multiple sclerosis: the present and the future. Arch Neurol. 2011;68:1514-20.

3. Kuchling J, Sinnecker T, Bozin I, Dörr J, Madai VI, Sobesky J, et al. Ultrahigh field MRI in context of neurological diseases. Nervenarzt. 2014;85(4):445-58

4. Golubnitschaja O, Costigliola V, EPMA. General report \& recommendations in predictive, preventive and personalised medicine 2012: white paper of the European Association for Predictive, Preventive and Personalised Medicine. EPMA J. 2012;3:1-53.

5. Haacke E, Brown R, Thompson M, Venkatesan R. Magnetic resonance imaging: physical principles and sequence design. John Wiley \& Sons (USA). 1999. p. 378

6. Moser E, Stahlberg F, Ladd ME, Trattnig S. 7-T MR — from research to clinical applications? NMR Biomed. 2012;25:695-716

7. Gizewski ER, Maderwald S, Linn J, Dassinger B, Bochmann K, Forsting M, et al. High-resolution anatomy of the human brain stem using 7-T MRI: improved detection of inner structures and nerves? Neuroradiology. 2014;56:177-86.

8. Strotmann B, Heidemann RM, Anwander A, Weiss M, Trampel R, Villringer A, et al. High-resolution MRI and diffusion-weighted imaging of the human habenula at 7 tesla. J Magn Reson Imaging. 2014;39:1018-26.

9. Graessl A, Renz W, Hezel F, Dieringer MA, Winter L, Oezerdem C, et al. Modular 32-channel transceiver coil array for cardiac MRI at 7.0T: modular transceiver coil array for cardiac MRI. Magn Reson Med. 2014;72:276-90.

10. Graessl A, Muhle M, Schwerter M, Rieger J, Oezerdem C, Santoro D, et al. Ophthalmic magnetic resonance imaging at $7 \mathrm{~T}$ using a 6-channel transceiver radiofrequency coil array in healthy subjects and patients with intraocular masses. Invest Radiol. 2014;49:260-70.

11. Thalhammer C, Renz W, Winter L, Hezel F, Rieger J, Pfeiffer $H$, et al Two-dimensional sixteen channel transmit/receive coil array for cardiac MRI at 7.0 T: design, evaluation, and application. J Magn Reson Imaging. 2012;36:847-57.

12. Atkinson IC, Renteria L, Burd H, Pliskin NH, Thulborn KR. Safety of human MRI at static fields above the FDA 8 T guideline: sodium imaging at 9.4 T does not affect vital signs or cognitive ability. J Magn Reson Imaging. 2007;26:1222-7.

13. Chakeres DW, Bornstein R, Kangarlu A. Randomized comparison of cognitive function in humans at 0 and 8 Tesla. J Magn Reson Imaging. 2003;18:342-5.

14. Theysohn J. Subjective acceptance of $7 \mathrm{~T}$ : initial experience in the first 210 subjects. Proc Intl Soc Mag Reson Med. 2008;16:1049.

15. Möller HE, von Cramon DY. Survey of risks related to static magnetic fields in ultra high field MRI. Rofo - Fortschr Rontg. 2008;180:293-301.

16. Fatahi M, Reddig A, Friebe B, Reinhold D, Speck O. Analysis of DNA double-strand breaks in human peripheral blood mononuclear cells after exposure to $7 \mathrm{~T} \mathrm{MRI}$. ISMRM Toronto, Canada. 2015;2015:0300.

17. Klix S, Els A, Paul K, Graessl A, Oezerdem C, Weinberger O, et al. On the subjective acceptance during cardiovascular magnetic resonance imaging at 7.0 Tesla. PLOS ONE. 2015;10:e0117095.

18. Chakeres DW, de Vocht F. Static magnetic field effects on human subjects related to magnetic resonance imaging systems. Prog Biophys Mol Biol. 2005;87:255-65.

19. Kangarlu A, Robitaille P-ML. Biological effects and health implications in magnetic resonance imaging. Concepts Magn Reson. 2000;12:321-59.

20. Lee JW, Kim MS, Kim YJ, Choi YJ, Lee Y, Chung HW. Genotoxic effects of 3 T magnetic resonance imaging in cultured human lymphocytes. Bioelectromagnetics. 2011;32:535-42.

21. Knuuti J, Saraste A, Kallio M, Minn H. Is cardiac magnetic resonance imaging causing DNA damage? Eur Heart J. 2013;34:2337-9.

22. Polman CH, Reingold SC, Banwell B, Clanet M, Cohen JA, Filippi M, et al. Diagnostic criteria for multiple sclerosis: 2010 revisions to the McDonald criteria. Ann Neurol. 2011;69:292-302.

23. Doering A, Pfueller CF, Paul F, Dörr J. Exercise in multiple sclerosis-an integral component of disease management. EPMA J. 2012;3:2.

24. Dörr J, Doering A, Paul F. Can we prevent or treat multiple sclerosis by individualised vitamin D supply. EPMA J. 2013;4:1-12.
25. Urbanek C, Weinges-Evers N, Bellmann-Strobl J, Bock M, Dorr J, Hahn E, et al. Attention Network Test reveals alerting network dysfunction in multiple sclerosis. Mult Scler J. 2010;16:93-9.

26. Weinges-Evers N, Brandt AU, Bock M, Pfueller CF, Dorr J, Bellmann-Strobl J, et al. Correlation of self-assessed fatigue and alertness in multiple sclerosis. Mult Scler J. 2010;16:1134-40.

27. Bellmann-Strobl J, Wuerfel J, Aktas O, Dörr J, Wernecke KD, Zipp F, et al. Poor PASAT performance correlates with MRI contrast enhancement in multiple sclerosis. Neurology. 2009;73:1624-7.

28. Veauthier C, Paul F. Fatigue in multiple sclerosis: which patient should be referred to a sleep specialist? Mult Scler J. 2012;18:248-9.

29. Finke C, Pech LM, Sömmer C, Schlichting J, Stricker S, Endres M, et al. Dynamics of saccade parameters in multiple sclerosis patients with fatigue. J Neurol. 2012;259:2656-63.

30. Wieder L, Gäde G, Pech LM, Zimmermann H, Wernecke K-D, Dörr J, et al. Low contrast visual acuity testing is associated with cognitive performance in multiple sclerosis: a cross-sectional pilot study. BMC Neurol. 2013;13:167.

31. Scheel M, Finke C, Oberwahrenbrock T, Freing A, Pech L, Schlichting J, et al. Retinal nerve fibre layer thickness correlates with brain white matter damage in multiple sclerosis: a combined optical coherence tomography and diffusion tensor imaging study. Mult Scler J. 2014;20:190-7.

32. Zimmermann H, Freing A, Kaufhold F, Gaede G, Bohn E, Bock M, et al. Optic neuritis interferes with optical coherence tomography and magnetic resonance imaging correlations. Mult Scler J. 2013;19:443-50.

33. Oberwahrenbrock T, Ringelstein M, Jentschke S, Deuschle K, Klumbies K, Bellmann-Strobl J, et al. Retinal ganglion cell and inner plexiform layer thinning in clinically isolated syndrome. Mult Scler J. 2013;19:1887-95.

34. Bock M, Brandt AU, Kuchenbecker J, Dorr J, Pfueller CF, Weinges-Evers N, et al. Impairment of contrast visual acuity as a functional correlate of retinal nerve fibre layer thinning and total macular volume reduction in multiple sclerosis. Br J Ophthalmol. 2012;96:62-7.

35. Bock M, Brandt AU, Dorr J, Pfueller CF, Ohlraun S, Zipp F, et al. Time domain and spectral domain optical coherence tomography in multiple sclerosis: a comparative cross-sectional study. Mult Scler J. 2010;16:893-6.

36. Brandt AU, Oberwahrenbrock T, Ringelstein M, Young KL, Tiede M, Hartung $\mathrm{HP}$, et al. Primary retinal pathology in multiple sclerosis as detected by optical coherence tomography. Brain. 2011;134:e193.

37. Simon J. Very early MS-insights from MRI. Mult Scler J. 2012;18:1372-6.

38. Londono AC, Mora CA. Nonconventional MRI biomarkers for in vivo monitoring of pathogenesis in multiple sclerosis. Neurol Neuroimmunol Neuroinflammation. 2014;1:e45.

39. Ciccarelli O, Barkhof F, Bodini B, De Stefano N, Golay X, Nicolay K, et al. Pathogenesis of multiple sclerosis: insights from molecular and metabolic imaging. Lancet Neurol. 2014;13:807-22.

40. Huhn K, Lämmer R, Oberwahrenbrock T, Lämmer A, Waschbisch A, Gosar D, et al. Optical coherence tomography in patients with a history of juvenile multiple sclerosis reveals early retinal damage. Eur J Neurol. 2015;22:86-92.

41. Finke C, Schlichting J, Papazoglou S, Scheel M, Freing A, Soemmer C, et al. Altered basal ganglia functional connectivity in multiple sclerosis patients with fatigue. Mult Scler J. 2015;21:925-34.

42. Pfueller CF, Brandt AU, Schubert F, Bock M, Walaszek B, Waiczies $H$, et al. Metabolic changes in the visual cortex are linked to retinal nerve fiber layer thinning in multiple sclerosis. PLOS ONE. 2011;6:e18019.

43. Bellmann-Strobl J, Stiepani H, Wuerfel J, Bohner G, Paul F, Warmuth C, et al. MR spectroscopy (MRS) and magnetisation transfer imaging (MTI), lesion load and clinical scores in early relapsing remitting multiple sclerosis: a combined cross-sectional and longitudinal study. Eur Radiol. 2009;19:2066-74.

44. Streitberger K-J, Sack I, Krefting D, Pfüller C, Braun J, Paul F, et al. Brain viscoelasticity alteration in chronic-progressive multiple sclerosis. PLoS ONE. 2012; 7:e29888

45. Charil A, Yousry TA, Rovaris M, Barkhof F, De Stefano N, Fazekas F, et al. MRI and the diagnosis of multiple sclerosis: expanding the concept of "no better explanation". Lancet Neurol. 2006;5:841-52.

46. Solomon AJ, Klein EP, Bourdette D. "Undiagnosing" multiple sclerosis: the challenge of misdiagnosis in MS. Neurology. 2012;78:1986-91.

47. Hohlfeld R. "Gimme five": future challenges in multiple sclerosis. ECTRIMS Lecture 2009. Mult Scler J. 2010;16:3-14.

48. Dörr J, Bitsch A, Schmailzl KJG, Chan A, Von Ahsen N, Hummel M, et al Severe cardiac failure in a patient with multiple sclerosis following low-dose mitoxantrone treatment. Neurology. 2009;73:991-3. 
49. Stroet A, Hemmelmann C, Starck M, Zettl U, Dörr J, Paul F, et al. Incidence of therapy-related acute leukaemia in mitoxantrone-treated multiple sclerosis patients in Germany. Ther Adv Neurol Disord. 2012;5:75-9.

50. Dörr J, Paul F. The transition from first-line to second-line therapy in multiple sclerosis. Curr Treat Options Neurol. 2015;17:354.

51. Borisow N, Doering A, Pfueller CF, Paul F, Dörr J, Hellwig K. Expert recommendations to personalization of medical approaches in treatment of multiple sclerosis: an overview of family planning and pregnancy. EPMA J. 2012;3:9.

52. Li V, Kane J, Chan HH, Hall AJ, Butzkueven H. Continuing fingolimod after development of macular edema: a case report. Neurol-Neuroimmunol Neuroinflammation. 2014;1:e13.

53. Clausi V, Giannecchini S, Magnani E, Repice A, Mechi C, Martelli F, et al. Markers of JC virus infection in patients with multiple sclerosis under natalizumab therapy. Neurol Neuroimmunol Neuroinflammation. 2015;2:e58-8.

54. Vennegoor A, van Rossum JA, Polman CH, Wattjes MP, Killestein J. Longitudinal JCV serology in multiple sclerosis patients preceding natalizumab-associated progressive multifocal leukoencephalopathy. Mult Scler J. 2015. doi:10.1177/1352458514567728.

55. Tallantyre EC, Morgan PS, Dixon JE, Al- RA, Brookes MJ, Morris PG, et al. 3 Tesla and 7 Tesla MRI of multiple sclerosis cortical lesions. J Magn Reson Imaging. 2010;32:971-7.

56. Magliozzi R, Howell O, Vora A, Serafini B, Nicholas R, Puopolo M, et al. Meningeal B-cell follicles in secondary progressive multiple sclerosis associate with early onset of disease and severe cortical pathology. Brain J Neurol. 2007;130:1089-104.

57. Schmierer K, Parkes HG, So P-W, An SF, Brandner S, Ordidge RJ, et al. High field (9.4 Tesla) magnetic resonance imaging of cortical grey matter lesions in multiple sclerosis. Brain J Neurol. 2010;133:858-67.

58. Kutzelnigg A, Lucchinetti CF, Stadelmann C, Brück W, Rauschka H, Bergmann $\mathrm{M}$, et al. Cortical demyelination and diffuse white matter injury in multiple sclerosis. Brain. 2005;128:2705-12.

59. Calabrese M, Poretto V, Favaretto A, Alessio S, Bernardi $V$, Romualdi $C$, et al, Cortical lesion load associates with progression of disability in multiple sclerosis. Brain J Neurol. 2012;135:2952-61.

60. DeLuca GC, Yates RL, Beale H, Morrow SA. Cognitive impairment in multiple sclerosis: clinical, radiologic and pathologic insights. Brain Pathol Zurich Switz. 2015;25:79-98.

61. Nielsen AS, Kinkel RP, Madigan N, Tinelli E, Benner T, Mainero C. Contribution of cortical lesion subtypes at $7 \mathrm{~T}$ MRI to physical and cognitive performance in MS. Neurology. 2013;81:641-9.

62. Geurts JJG, Bö L, Pouwels PJW, Castelijns JA, Polman CH, Barkhof F. Cortical lesions in multiple sclerosis: combined postmortem MR imaging and histopathology. Am J Neuroradiol. 2005;26:572-7.

63. Geurts JJG, Pouwels PJW, Uitdehaag BMJ, Polman CH, Barkhof F, Castelijns JA. Intracortical lesions in multiple sclerosis: improved detection with 3D double inversion-recovery MR imaging. Radiology. 2005;236:254-60.

64. Yao B, Hametner S, van Gelderen P, Merkle H, Chen C, Lassmann H, et al. 7 Tesla magnetic resonance imaging to detect cortical pathology in multiple sclerosis. PloS One. 2014;9:e108863.

65. Abdel-Fahim R, Mistry N, Mougin O, Blazejewska A, Pitiot A, Retkute R, et al. Improved detection of focal cortical lesions using 7T magnetisation transfer imaging in patients with multiple sclerosis. Mult Scler Relat Disord. 2014;3:258-65.

66. Kilsdonk ID, de Graaf WL, Soriano AL, Zwanenburg JJ, Visser F, Kuijer JPA, et al. Multicontrast MR imaging at 7T in multiple sclerosis: highest lesion detection in cortical gray matter with 3D-FLAIR. Am J Neuroradiol. 2013:34:791-6.

67. de Graaf WL, Kilsdonk ID, Lopez-Soriano A, Zwanenburg JJM, Visser F, Polman $\mathrm{CH}$, et al. Clinical application of multi-contrast 7-T MR imaging in multiple sclerosis: increased lesion detection compared to $3 \mathrm{~T}$ confined to grey matter. Eur Radiol. 2013;23:528-40.

68. Sinnecker T, Mittelstaedt P, Dörr J, Pfueller CF, Harms L, Niendorf T, et al. Multiple sclerosis lesions and irreversible brain tissue damage: a comparative ultrahigh-field strength magnetic resonance imaging study. Arch Neurol. 2012;69:739-45.

69. Nielsen AS, Kinkel RP, Tinelli E, Benner T, Cohen-Adad J, Mainero C. Focal cortical lesion detection in multiple sclerosis: 3 Tesla DIR versus 7 Tesla FLASH-T2. J Magn Reson Imaging. 2012;35:537-42.

70. Peterson JW, Bö L, Mörk S, Chang A, Trapp BD. Transected neurites, apoptotic neurons, and reduced inflammation in cortical multiple sclerosis lesions. Ann Neurol. 2001;50:389-400.
71. Kollia K, Maderwald S, Putzki N, Schlamann M, Theysohn JM, Kraff O, et al. First clinical study on ultra-high-field MR imaging in patients with multiple sclerosis: comparison of 1.5T and 7T. Am J Neuroradiol. 2009;30:699-702.

72. Mainero C, Benner T, Radding A, van der Kouwe A, Jensen R, Rosen BR, et al. In vivo imaging of cortical pathology in multiple sclerosis using ultra-high field MRI. Neurology. 2009;73:941-8.

73. Pitt D, Boster A, Pei W, Wohleb E, Jasne A, Zachariah $C R$, et al. Imaging cortical lesions in multiple sclerosis with ultra-high-field magnetic resonance imaging. Arch Neurol. 2010;67:812-8.

74. Metcalf M, Xu D, Okuda DT, Carvajal L, Srinivasan R, Kelley DAC, et al. High-resolution phased-array MRI of the human brain at 7 tesla: initial experience in multiple sclerosis patients. J Neuroimaging Off J Am Soc Neuroimaging. 2010;20:141-7.

75. Fischer MT, Wimmer I, Höftberger R, Gerlach S, Haider L, Zrzavy T, et al. Disease-specific molecular events in cortical multiple sclerosis lesions. Brain J Neurol. 2013;136:1799-815.

76. Cohen-Adad J, Benner T, Greve D, Kinkel RP, Radding A, Fischl B, et al. In vivo evidence of disseminated subpial $\mathrm{T}^{*}$ signal changes in multiple sclerosis at 7 T: a surface-based analysis. Neurolmage. 2011;57:55-62.

77. Harrison DM, Oh J, Roy S, Wood ET, Whetstone A, Seigo MA, et al. Thalamic lesions in multiple sclerosis by 7T MRI: clinical implications and relationship to cortical pathology. Mult Scler J. 2015 doi:10.117/1352458514558134

78. van Walderveen MA, Barkhof F, Hommes OR, Polman CH, Tobi H, Frequin ST, et al. Correlating MRI and clinical disease activity in multiple sclerosis: relevance of hypointense lesions on short-TR/short-TE (T1-weighted) spin-echo images. Neurology. 1995;45:1684-90.

79. Sailer M, Losseff NA, Wang L, Gawne-Cain ML, Thompson AJ, Miller DH. T1 lesion load and cerebral atrophy as a marker for clinical progression in patients with multiple sclerosis. A prospective 18 months follow-up study. Eur J Neurol Off J Eur Fed Neurol Soc. 2001;8:37-42.

80. Mistry N, Tallantyre EC, Dixon JE, Galazis N, Jaspan T, Morgan PS, et al. Focal multiple sclerosis lesions abound in "normal appearing white matter". Mult Scler J. 2011;17:1313-23.

81. Tallantyre EC, Morgan PS, Dixon JE, Al- RA, Brookes MJ, Evangelou N, et al. A comparison of $3 \mathrm{~T}$ and $7 \mathrm{~T}$ in the detection of small parenchymal veins within MS lesions. Invest Radiol. 2009;44:491-4.

82. Tallantyre EC, Brookes MJ, Dixon JE, Morgan PS, Evangelou N, Morris PG. Demonstrating the perivascular distribution of MS lesions in vivo with 7-Tesla MRI. Neurology. 2008;70:2076-8.

83. Kuchling J, Ramien C, Bozin I, Dörr J, Harms L, Rosche B, et al. Identical lesion morphology in primary progressive and relapsing-remitting MS-an ultrahigh field MRI study. Mult Scler J. 2014;20:1866-71.

84. Absinta M, Sati P, Gaitán MI, Maggi P, Cortese ICM, Filippi M, et al. Seven-tesla phase imaging of acute multiple sclerosis lesions: a new window into the inflammatory process. Ann Neurol. 2013;74:669-78.

85. Bian W, Harter K, Hammond-Rosenbluth KE, Lupo JM, Xu D, Kelley DA, et al. A serial in vivo $7 T$ magnetic resonance phase imaging study of white matter lesions in multiple sclerosis. Mult Scler J. 2013;19:69-75.

86. Radaideh AM A, Wharton SJ, Lim S-Y, Tench CR, Morgan PS, Bowtell RW, et al. Increased iron accumulation occurs in the earliest stages of demyelinating disease: an ultra-high field susceptibility mapping study in Clinically Isolated Syndrome. Mult Scler J. 2013;19:896-903.

87. Hametner S, Wimmer I, Haider L, Pfeifenbring S, Brück W, Lassmann H. Iron and neurodegeneration in the multiple sclerosis brain. Ann Neurol. 2013;74:848-61.

88. Bagnato F, Hametner S, Yao B, van Gelderen P, Merkle H, Cantor FK, et al. Tracking iron in multiple sclerosis: a combined imaging and histopathological study at 7 Tesla. Brain J Neurol. 2011;134:3602-15.

89. Adams CW. Perivascular iron deposition and other vascular damage in multiple sclerosis. J Neurol Neurosurg Psychiatry. 1988:51:260-5.

90. Bozin I, Ge Y, Kuchling J, Dusek P, Chawla S, Harms L, et al. Magnetic resonance phase alterations in multiple sclerosis patients with short and long disease duration. PLoS One. 2015;10(7):e0128386.

91. Connor JR, Menzies SL. Relationship of iron to oligodendrocytes and myelination. Glia. 1996;17:83-93.

92. Sinnecker T, Dörr J, Pfueller CF, Harms L, Ruprecht K, Jarius S, et al. Distinct lesion morphology at 7-T MRI differentiates neuromyelitis optica from multiple sclerosis. Neurology. 2012;79:708-14.

93. Kister I, Herbert J, Zhou Y, Ge Y. Ultrahigh-field MR (7 T) imaging of brain lesions in neuromyelitis optica. Mult Scler Int. 2013. doi:10.1155/2013/ 398259. 
94. Tallantyre EC, Dixon JE, Donaldson I, Owens T, Morgan PS, Morris PG, et al. Ultra-high-field imaging distinguishes MS lesions from asymptomatic white matter lesions. Neurology. 2011;76:534-9.

95. Wuerfel J, Sinnecker T, Ringelstein EB, Jarius S, Schwindt W, Niendorf T, et al. Lesion morphology at 7 Tesla MRI differentiates Susac syndrome from multiple sclerosis. Mult Scler J. 2012;18:1592-9.

96. Mistry N, Dixon J, Tallantyre E, Tench C, Abdel-Fahim R, Jaspan T, et al. Central veins in brain lesions visualized with high-field magnetic resonance imaging: a pathologically specific diagnostic biomarker for inflammatory demyelination in the brain. JAMA Neurol. 2013;70:623-8.

97. Paul F, Wattjes MP. Chronic cerebrospinal venous insufficiency in multiple sclerosis: the final curtain. Lancet. 2014;383:106-8.

98. Valdueza JM, Doepp F, Schreiber SJ, van Oosten BW, Schmierer K, Paul F, et al. What went wrong? The flawed concept of cerebrospinal venous insufficiency. J Cereb Blood Flow Metab. 2013;33:657-68.

99. Doepp F, Paul F, Valdueza JM, Schmierer K, Schreiber SJ. No cerebrocervical venous congestion in patients with multiple sclerosis. Ann Neurol. 2010;68:173-83.

100. Doepp F, Wuerfel JT, Pfueller CF, Valdueza JM, Petersen D, Paul F, et al Venous drainage in multiple sclerosis: a combined MRI and ultrasound study. Neurology. 2011;77:1745-51.

101. Dawson J. The histology of disseminated sclerosis. Trans Roy Soc Edin. 1916:50:517-740

102. Müller K, Kuchling J, Dörr J, Harms L, Ruprecht K, Niendorf T, et al. Detailing intra-lesional venous lumen shrinking in multiple sclerosis investigated by sFLAIR MRI at 7-T. J Neurol. 2014;261:2032-6.

103. Sinnecker T, Bozin I, Dörr J, Pfueller CF, Harms L, Niendorf T, et al. Periventricular venous density in multiple sclerosis is inversely associated with T2 lesion count: a 7 Tesla MRI study. Mult Scler J. 2013;19:316-25.

104. Gaitán MI, de Alwis MP, Sati P, Nair G, Reich DS. Multiple sclerosis shrinks intralesional, and enlarges extralesional, brain parenchymal veins. Neurology. 2013:80:145-51.

105. Adams CW, Poston RN, Buk SJ, Sidhu YS, Vipond H. Inflammatory vasculitis in multiple sclerosis. J Neurol Sci. 1985;69:269-83.

106. Sinnecker T, Oberwahrenbrock T, Metz I, Zimmermann H, Pfueller CF, Harms L, et al. Optic radiation damage in multiple sclerosis is associated with visual dysfunction and retinal thinning — an ultrahigh-field MR pilot study. Eur Radiol. 2014:25:122-31.

107. Marques JP, Kober T, Krueger G, van der Zwaag W, Van de Moortele P-F, Gruetter R. MP2RAGE, a self bias-field corrected sequence for improved segmentation and T1-mapping at high field. Neurolmage. 2010;49:1271-81.

108. Fujimoto K, Polimeni JR, van der Kouwe AJW, Reuter M, Kober T, Benner T, et al. Quantitative comparison of cortical surface reconstructions from MP2RAGE and multi-echo MPRAGE data at 3 and 7 T. Neurolmage. 2014;90:60-73.

109. Seiger R, Hahn A, Hummer A, Kranz GS, Ganger S, Küblböck M, et al. Voxel-based morphometry at ultra-high fields. A comparison of 7T and 3T MRI data. Neurolmage. 2015;113:207-16.

110. O'Brien KR, Kober T, Hagmann P, Maeder P, Marques J, Lazeyras F, et al. Robust T1-weighted structural brain imaging and morphometry at $7 \mathrm{~T}$ using MP2RAGE. PloS One. 2014:9:e99676.

111. Jarius S, Ruprecht K, Wildemann B, Kuempfel T, Ringelstein M, Geis C, et al. Contrasting disease patterns in seropositive and seronegative neuromyelitis optica: a multicentre study of 175 patients. J Neuroinflammation. 2012:9:14.

112. Jarius S, Wildemann B, Paul F. Neuromyelitis optica: clinical features, immunopathogenesis and treatment. Clin Exp Immunol. 2014;176:149-64.

113. Lucchinetti CF, Mandler RN, McGavern D, Bruck W, Gleich G, Ransohoff RM et al. A role for humoral mechanisms in the pathogenesis of Devic's neuromyelitis optica. Brain. 2002;125:1450-61.

114. Lennon VA, Kryzer TJ, Pittock SJ, Verkman AS, Hinson SR. IgG marker of optic-spinal multiple sclerosis binds to the aquaporin-4 water channel. J Exp Med. 2005;202:473-7

115. Jarius S, Franciotta D, Paul F, Bergamaschi R, Rommer PS, Ruprecht K, et al. Testing for antibodies to human aquaporin-4 by ELISA: sensitivity, specificity, and direct comparison with immunohistochemistry. J Neurol Sci. 2012;320:32-7.

116. Jarius S, Paul F, Fechner K, Ruprecht K, Kleiter I, Franciotta D, et al. Aquaporin-4 antibody testing: direct comparison of M1-AQP4-DNAtransfected cells with leaky scanning versus M23-AQP4-DNA-transfected cells as antigenic substrate. J Neuroinflammation. 2014;11:129.
117. Kister I, Paul F. Pushing the boundaries of neuromyelitis optica: does antibody make the disease? Neurology. 2015. doi:10.1212/WNL.0000000000001749.

118. Hertwig L, Pache F, Romero-Suarez S, Stürner KH, Borisow N, Behrens $J$, et al. Distinct functionality of neutrophils in multiple sclerosis and neuromyelitis optica. Mult Scler J. 2015. doi:10.1177/1352458515586084.

119. Jarius S, Paul F, Franciotta D, Waters P, Zipp F, Hohlfeld R, et al. Mechanisms of disease: aquaporin-4 antibodies in neuromyelitis optica. Nat Clin Pract Neurol. 2008:4:202-14.

120. Paul F, Jarius S, Aktas O, Bluthner M, Bauer O, Appelhans H, et al. Antibody to aquaporin 4 in the diagnosis of neuromyelitis optica. PLoS Med. 2007:4:669.

121. Bennett JL, de Seze J, Lana-Peixoto M, Palace J, Waldman A Schippling S, et al. Neuromyelitis optica and multiple sclerosis: seeing differences through optical coherence tomography. Mult Scler J. 2015:21:678-88

122. Schneider E, Zimmermann H, Oberwahrenbrock T, Kaufhold F, Kadas EM, Petzold A, et al. Optical coherence tomography reveals distinct patterns of retinal damage in neuromyelitis optica and multiple sclerosis. PLoS ONE. 2013;8:e66151.

123. Shimizu J, Hatanaka Y, Hasegawa M, Iwata A, Sugimoto I, Date $H$, et al. IFNß-1b may severely exacerbate Japanese optic-spinal MS in neuromyelitis optica spectrum. Neurology. 2010;75:1423-7.

124. Cree Ba C, Lamb S, Morgan K, Chen A, Waubant E, Genain C. An open label study of the effects of rituximab in neuromyelitis optica. Neurology. 2005;64:1270-2

125. Kleiter I, Hellwig K, Berthele A, Kümpfel T, Linker RA, Hartung H-P, et al. Failure of natalizumab to prevent relapses in neuromyelitis optica. Arch Neurol. 2012:69:239-45.

126. Trebst C, Jarius S, Berthele A, Paul F, Schippling S, Wildemann B, et al. Update on the diagnosis and treatment of neuromyelitis optica: recommendations of the Neuromyelitis Optica Study Group (NEMOS). J Neurol. 2014;261:1-16.

127. Min J-H, Kim BJ, Lee KH. Development of extensive brain lesions following fingolimod (FTY720) treatment in a patient with neuromyelitis optica spectrum disorder. Mult Scler J. 2012;18:113-5.

128. Jarernsook B, Siritho S, Prayoonwiwat N. Efficacy and safety of beta-interferon in Thai patients with demyelinating diseases. Mult Scler J. 2012;19:585-92

129. Pittock SJ, Lennon VA, Krecke K, Wingerchuk DM, Lucchinetti CF, Weinshenker BG. Brain abnormalities in neuromyelitis optica. Arch Neurol. 2006:63:390-6.

130. Matthews L, Marasco R, Jenkinson M, Küker W, Luppe S, Leite Ml, et al. Distinction of seropositive NMO spectrum disorder and MS brain lesion distribution. Neurology. 2013;80:1330-7.

131. Kim HJ, Paul F, Lana-Peixoto MA, Tenembaum S, Asgari N, Palace J, et al. MRI characteristics of neuromyelitis optica spectrum disorder: an international update. Neurology. 2015:84:1165-73.

132. Flanagan EP, Weinshenker BG, Krecke KN, Lennon VA, Lucchinetti CF, Mckeon A, et al. Short myelitis lesions in aquaporin-4-lgG-positive neuromyelitis optica spectrum disorders. JAMA Neurol. 2015;72:81.

133. Susac JO, Hardman JM, Selhorst JB. Microangiopathy of the brain and retina. Neurology. 1979;29:313-6.

134. Susac JO. Susac's syndrome: the triad of microangiopathy of the brain and retina with hearing loss in young women. Neurology. 1994;44:591-3.

135. Dörr J, Radbruch H, Bock M, Wuerfel J, Brüggemann A, Wandinger KP, et al. Encephalopathy, visual disturbance and hearing loss-recognizing the symptoms of Susac syndrome. Nat Rev Neurol. 2009:5:683-8.

136. Dörr J, Krautwald S, Wildemann B, Jarius S, Ringelstein M, Duning T, et al. Characteristics of Susac syndrome: a review of all reported cases. Nat Rev Neurol. 2013;9:307-16.

137. Jarius S, Kleffner I, Dörr JM, Sastre-Garriga J, Illes Z, Eggenberger E, et al. Clinical, paraclinical and serological findings in Susac syndrome: an international multicenter study. J Neuroinflammation. 2014;11:46.

138. Brandt AU, Zimmermann H, Kaufhold F, Promesberger J, Schippling S, Finis D et al. Patterns of retinal damage facilitate differential diagnosis between Susac syndrome and MS. PLOS ONE. 2012;7:e38741.

139. Ringelstein M, Albrecht $P$, Kleffner I, Bühn B, Harmel J, Müller A, et al. Retinal pathology in Susac syndrome detected by spectral-domain optical coherence tomography. Neurology. 2015;85(7):610-8.

140. Dörr J, Jarius S, Wildemann B, Ringelstein EB, Schwindt W, Deppe $M$, et al. Susac syndrome: an interdisciplinary challenge. Nervenarzt. 2011;82:1250-63. 
141. Dörr J, Ringelstein M, Duning T, Kleffner I. Update on Susac syndrome: new insights in brain and retinal imaging and treatment options. J Alzheimers Dis. 2014;42 Suppl 3:S99-108

142. Rennebohm RM, Egan RA, Susac JO. Treatment of Susac's Syndrome. Curr Treat Options Neurol. 2008;10:67-74.

143. Saux A, Niango G, Charif M, Morales R, Mura F, Bonafe A, et al. Susac's syndrome, a rare, potentially severe or lethal neurological disease. J Neurol Sci. 2010;297:71-3.

144. Susac JO, Murtagh FR, Egan RA, Berger JR, Bakshi R, Lincoff N, et al. MRI findings in Susac's syndrome. Neurology. 2003;61:1783-7.

145. Kilsdonk ID, Wattjes MP, Lopez-Soriano A, Kuijer JPA, de Jong MC, de Graaf WL, et al. Improved differentiation between MS and vascular brain lesions using FLAIR* at 7 Tesla. Eur Radiol. 2014;24:841-9.

146. Sati P, George IC, Shea CD, Gaitán MI, Reich DS. FLAIR*: a combined MR contrast technique for visualizing white matter lesions and parenchymal veins. Radiology. 2012;265:926-32.

147. Grabner G, Dal-Bianco A, Schernthaner M, Vass K, Lassmann H, Trattnig S. Analysis of multiple sclerosis lesions using a fusion of 3.0 T FLAIR and 7.0 T SWI phase: FLAIR SWI. J Magn Reson Imaging. 2011;33:543-9.

148. Dixon JE, Simpson A, Mistry N, Evangelou N, Morris PG. Optimisation of T2*-weighted MRI for the detection of small veins in multiple sclerosis at $3 \mathrm{~T}$ and 7 T. Eur J Radiol. 2013;82:719-27.

\section{Submit your next manuscript to BioMed Central and take full advantage of:}

- Convenient online submission

- Thorough peer review

- No space constraints or color figure charges

- Immediate publication on acceptance

- Inclusion in PubMed, CAS, Scopus and Google Scholar

- Research which is freely available for redistribution 